\section{No meio do caminho havia os Bororo. Jarudori MT, a diáspora e reterritorialização}

\author{
Antonio Hilário Aguilera Urquiza
}

Resumo: Tendo por base o estudo e levantamento histórico-antropológico da Terra indígena de Jarudori, realizado pela profa. Dra. Edir Pina de Barros, antropóloga, e pelo historiador Mário Bordignon, a pedido da FUNAI e do Ministério Público Federal, em 2003, o presente texto tem por objetivo ressaltar os aspectos da diáspora (devido à ocupação pelos brancos de suas terras) e de reterritorialização levados a cabo pelos Bororo atuais. Tem, também, como proposta, neste momento de crescentes tensões na disputa pela terra, trazer para o debate público elementos fundamentais para a compreensão do processo de expropriação sofrida pelos Bororo durante o século XX. O artigo retoma aspectos desse processo histórico de perda do território ancestral dos Bororo, reconhecido e demarcado pelo marechal Rondon, na região leste de Mato Grosso, entre as cidades de Rondonópolis e Poxoréo, as conseqüências dessa perda e o movimento atual de pressão pela retomada legítima de suas terras. $\mathrm{O}$ caso de Jarudori é sui generis, por tratar-se de uma área indígena reconhecida, demarcada e homologada, mas que na atualidade é ocupada por fazendeiros e por uma cidade do mesmo nome, distrito do município de Poxoréo/Mato Grosso.

Palavras-chave: índios Bororo; terra indígena Jarudori; levantamento histórico-antropológico.

Abstract: Having as a basis the study and historical-anthropological
survey of the indigenous Land of Jarudori, carried out by Professor Doctor
Edir Pina de Barros, anthropologist, and, the historian Mário Bordignon,
at the request of the National Indian Foundation and the Federal Public
Ministry, in 2003, the text in hand aims as bringing out aspects of the
diaspora (because of the white occupation of their land) and the territorial
return taken seriously by present day Bororo. There is also the proposal,
at this time of growing tensions over the dispute for land, to bring to the
public debate fundamental elements for the understanding of the process
of expropriation suffered by the Bororo during the $20^{\text {th }}$ century. The article
takes up aspects of this historical process of the loss of Bororo ancestral
territory, recognized and demarcated by Marshall Rondon, in the eastern
region of Mato Grosso, between the cities of Rondonópolis and Poxoréo,
the consequences of this loss and the present movement of pressure for
Doutor em Antropologia pela Universidade de Salamanca (Espanha); professor pesquisador da UFMS; membro do grupo de pesquisa sobre Educação Indígena e GEFIL - Grupo de Estudos e Pesquisas Filosóficas. hilario_aguilera@yahoo.es 
the legitimate retaking of their lands. The case of Jarudori is sui generis, as it handles a recognized indigenous area, demarcated and homologated, but which at the moment is occupied by farmers and by a city of the same name, district of the municipality of Poxoréo/Mato Grosso.

Key words: Bororo indians; indigenous land; Jarudori; historical-anthropological survey.

\section{Introdução}

O presente texto ${ }^{1}$ quer tratar dos elementos históricos e antropológicos que envolvem a Terra Indígena (TI) Bororo de Jarudori, na região sudoeste de Mato Grosso, uma área invadida desde o século passado. Seus habitantes, expulsos, vivem, temporariamente, em outras terras indígenas Bororo e alguns na periferia de Cuiabá, capital do Estado. Apoiados por entidades indigenistas e pelo próprio Ministério Público Federal, eles reivindicam seus direitos reconhecidos, inclusive pelos seus próprios invasores.

Após longo tempo de dispersão, para longe da área de Jarudori, um território significativo para todos os Bororo, algumas lideranças começaram a se organizar e reivindicar junto ao poder público a posse de suas terras. Trata-se de uma situação singular, sui generis, pois a terra que foi reservada pelo então Marechal Rondon², posteriormente demarcada e homologada pela união e, efetivamente, ocupada pelos indígenas até a década de 1970, na atualidade encontra-se totalmente tomada por não-indígenas, inclusive com a formação de uma cidadela com o mesmo nome da TI (Jarudori, distrito de Poxoréo ${ }^{3}$ ).

Em 2002, a pedido do Ministério Público Federal, a FUNAI (Fundação Nacional do Índio) constitui um grupo técnico ${ }^{4}$, para realizar estudos históricos e antropológicos com o objetivo de produzir subsídios para procedimentos jurídicos que viabilizem a reintegração de posse aos índios e o domínio da União sobre a Terra Indígena de Jarudori. É com base nos dados levantados por este estudo, em outras fontes bibliográficas (Viertler, 1990; Vangelista, 1996; Serpa, 1988; Gontijo, 1988) e, na experiência pessoal de pesquisador da cultura Bororo, que se fundamenta teórica e empiricamente o presente texto.

Além do recenseamento e minucioso levantamento histórico-documental, os autores (Barros; Bordignon, 2003) recorreram a inúmeras entrevistas com moradores locais (Jarudori e Poxoréo), particularmente os mais antigos e, com os Bororo que viviam em Jarudori até a década de 
1970, quando de lá saíram as últimas famílias indígenas.

Com base na Constituição Federal de 1988, artigo 231, capítulo VIII, que reconhece aos índios "sua organização social, costumes, línguas, crenças e tradições, e os direitos originários sobre as terras que tradicionalmente ocupam", os autores (Barros; Bordignon, 2003) partem do pressuposto da impossibilidade, em termos etno-históricos e sócio-antropológicos de tratar de forma separada os "Bororo de Jarudóri", pois eles são parte integrante da sociedade Bororo e como tal devem ser tratados e analisados. O direito à Terra Indígena Jarudóri é garantido aos Bororo, como unidade sociológica e historicamente constituída e não aos "Bororo de Jarudóri". Trata-se, em outras palavras, daquelas terras que são por eles habitadas em caráter permanente; as utilizadas para suas atividades produtivas; as imprescindíveis à preservação dos recursos ambientais necessários a seu bem-estar; e as necessárias à sua reprodução física e cultural, segundo seus usos, costumes e tradições.

Ainda no citado artigo 231, declara que as Terras Indígenas "destinam-se a sua posse permanente, cabendo-lhes o usufruto exclusivo das riquezas do solo, dos rios e dos lagos nelas existentes"; $\mathrm{e}$ "são inalienáveis eindisponíveis, e os direitos sobre elas, imprescritíveis". É necessário sublinhar que a nova carta Magna vedou a remoção dos grupos indígenas de suas terras, exceto "em caso de catástrofe ou epidemia que ponha em risco sua população, ou no interesse da soberania do País", ad referendum do Congresso Nacional, garantindo-lhes, contudo, "em qualquer hipótese, o retorno imediato logo que cesse o risco" (Barros; Bordignon, 2003, p.7).

Reafirmando o sentido da legislação o antropólogo João Dal Poz observa que:

A identificação e a caracterização das terras indígenas, desta maneira, devem pautar-se no exame minucioso das formas singulares de uso dos recursos naturais pela população indígena respectiva, da sua organização social e da distribuição espacial dos seus contingentes demográficos, dos vínculos morais e mitológicos que mantém com um certo conjunto de acidentes geográficos, da percepção histórica de suas relações com os lugares onde viveram e morreram seus antepassados, das suas convicções genuínas de um porvir enquanto sociedade culturalmente distinta (Dal Poz, 2002).

No entanto, para compreender a questão histórica que levou à exclusão dos Bororo de suas próprias terras, há que se tratar do processo de ocupação e da expansão do capital na região, assim como da política indigenista, uma de suas múltiplas faces. 


\section{No meio do caminho da expansão capitalista}

Mato Grosso constituiu, até meados do século passado, como bem colocara Chiara Evangelista (1996, p.165) “a expressão mais duradoura da fronteira brasileira", sendo palco de "ondas sucessivas de ocupação de seu território", conquistado aos indígenas e espanhóis. A ocupação do leste mato-grossense iniciou-se na primeira década do século XIX e intensificou-se em fins desse século e início do século XX, sobretudo, com a extração de pedras preciosas no "triângulo dos diamantes", como dizem os geógrafos.

Na década de 40 do século passado,

Mato Grosso foi o principal destinatário de uma campanha do regime populista de Getúlio Vargas denominada Marcha para o Oeste, com a qual se pretendia abrir uma nova fronteira: econômica, política, social, mas, sobretudo ideológica. Ainda que, do ponto de vista do seu discurso, tal marcha se voltasse para a região mais ocidental, em Mato Grosso favoreceu a ocupação de sua parte mais meridional (Evangelista, 1996, p.166).

O projeto de instituir um sistema estável de comunicações - através das linhas telegráficas, de vias terrestres e fluviais - de ocupá-la com a agricultura e a pecuária, "foi favorecida pela província e, depois, pelo governo federal. Era um projeto que exigia antes de tudo a neutralização dos Bororo, que freqüentemente atacavam os viajantes que percorriam a velha estrada de Goiás e os habitantes dos poucos ranchos espalhados pela zona" (Evangelista, 1996, p.168). Trata-se dos Bororo Orientais, senhores imemoriais dessas terras, atacados por expedições militares, organizadas pelo governo provincial e para-militares, durante quase todo o século XIX.

A partir da década de 1980 do século XIX, tendo em vista os interesses colonialistas em jogo, as ações indigenistas são orientadas por uma política de "atração", de reagrupamento e concentração desses Bororo, visando a liberação de suas terras para a ocupação das frentes econômicas que nela se sucederam (Barros \& Bordignon, 2003, p.9).

As colônias militares, instaladas no rio São Lourenço a partir de 1886, tornam-se núcleos de reunião de Bororo. Para isso igualmente contribuíram a construção das linhas telegráficas Goiás-Cuiabá, a partir de 1890 e a atuação de missionários salesianos, a partir de 1895. Assim, militares e salesianos ${ }^{5}$ constituíram os principais agentes do projeto de consolidação da fronteira nacional nessa importante parcela do território imemorial desse povo. 
Mapa 1 - Localização das terras indígenas Bororo no coração da América do Sul.

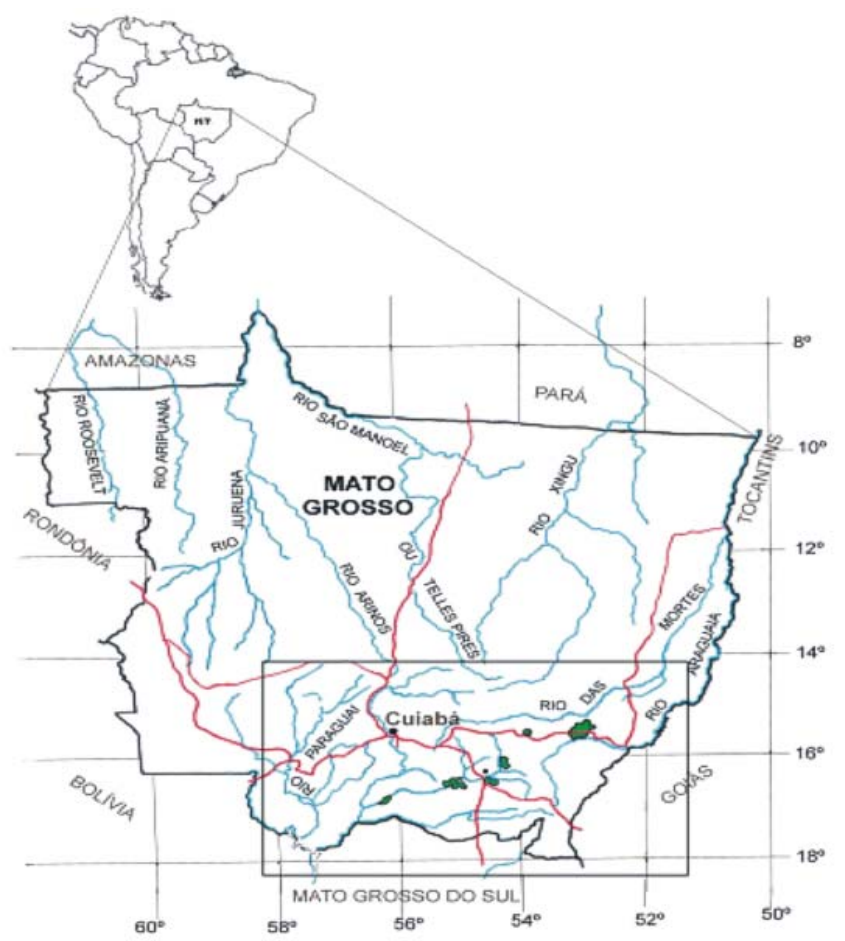

Fonte: Barros; Bordignon, 2003, p.3.

No início do século XX o território Bororo já estava drasticamente reduzido: rio das Garças, a leste; o rio Cuiabá, a oeste; o rio das Mortes, ao norte e o baixo rio São Lourenço e o rio Itiquira, ao sul (cf. Colbacchini \& Albisetti, 1942, p.29; Wüst, 1990, p.86).

A partir da última década do século XIX, os Bororo estabelecidos na área da bacia do rio Vermelho e afluentes do Araguaia, até o rio das Mortes - conhecidos na etnologia como Bororo "independentes" (Serpa, 1988, p.49; Viertler, 1990, dentre outros) ou "livres" (Wust, 1990, p.99), tiveram seu território invadido, de forma inexorável, por várias frentes de colonização. Forças políticas e econômicas compunham o campo de relações entre Bororo e colonizadores, dentre elas: a implantação das linhas telegráficas; a Missão Salesiana; as frentes agropastoris vindas de Goiás e Minas Gerais; a frente extrativista de diamantes, composta, sobretudo, por nordestinos; a implantação de colônias agrícolas pelo Estado de Mato Grosso, inclusive em terras demarcadas para os Bororo; a Fundação Brasil Central. 
Todos esses fatores entrelaçando-se no tempo e no espaço em foco, seja por presença ou por omissão, foram perpassados por questões de fronteira entre Mato Grosso e Goiás. Em meio a todos esses fatores, estavam os Bororo, particularmente os localizados na região do rio Vermelho (afluente do rio São Lourenço), rio das Mortes e afluentes do Rio Araguaia.

Mapa 2 - Terras indígenas Bororo (atuais).

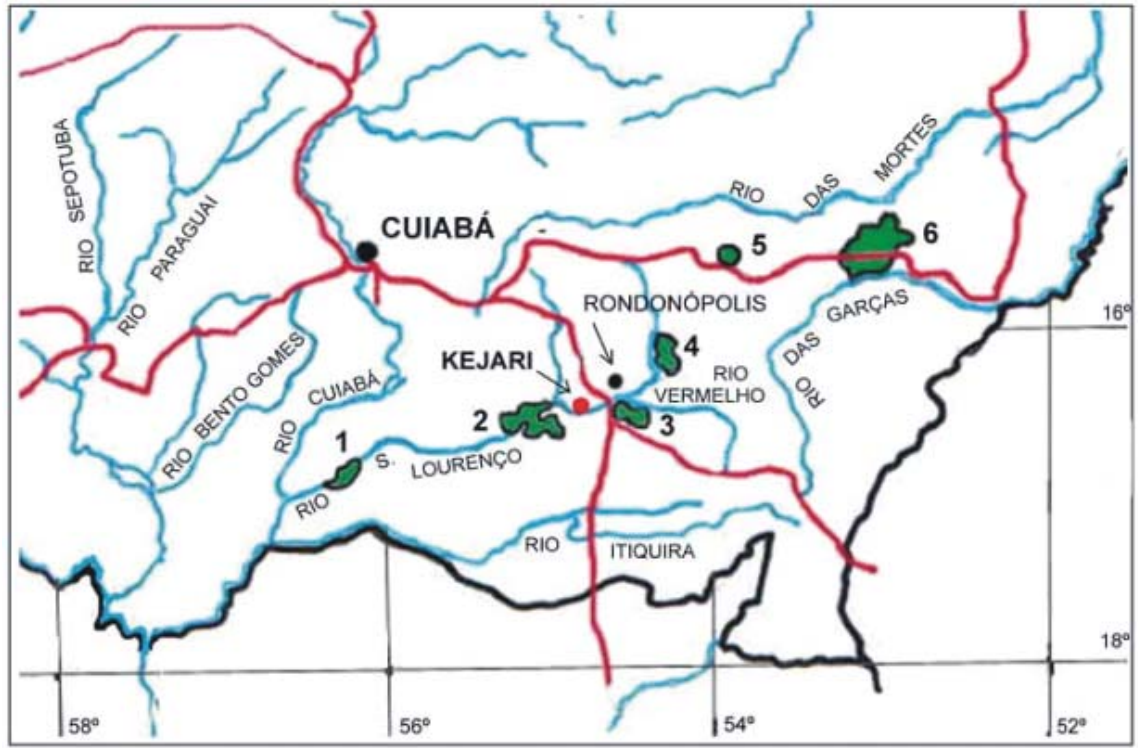

1 - T. I. PERIGARA - Município de Barão de Melgaço.

2 - T. I. TEREZA CRISTINA - Municípios de: Santo Antonio de Leveger, Juscimeira e Rondonópolis.

3 - T. I. TADARIMANA - Municípios de: Rondonópolis, São José do Povo e Pedra Preta.

4 - T. I. JARUDORI - Município dePoxoréu.

5 - T. I. SANGRADOURO - Município de General Carneiro (Em estudo).

6 - T. I. MERURI - Municípios de: General Carneiro e Barra do Garças.

Fonte: Barros; Bordignon, 2003, p.4.

Com a criação da Comissão Construtora de Linhas Telegráficas, em 1888, o governo imperial buscou viabilizar a segurança e o desenvolvimento de regiões mais distantes, favorecendo a sua comunicação com a capital do império, o Rio de Janeiro (Cf. Souza Lima, 1992). Em 1890 após a proclamação da República, foi criada a Comissão Construtora das Linhas Telegráficas de Cuiabá ao Araguaia, cortando outra parcela de território Bororo. Percebe-se que o processo de centralização das comunicações é paralelo à centralização do poder, tendo como conseqüência imediata a diminuição da autonomia. Os "aborígines" não ficaram imunes aos benefícios do progresso. 
Segundo Viertler (1990, p.70), na construção da linha telegráfica de Coxim (antiga colônia militar do Taquari fundada em 1862) a São Lourenço, diante das dificuldades encontradas - doenças, deserções e mortes - Rondon pediu ajuda aos Bororo da área, que freqüentavam os acampamentos da expedição para colaborarem no empreendimento. No início do século XX outras linhas foram instaladas, recrutando os Bororo, que denunciavam aos militares da Comissão a invasão de suas terras e as atrocidades contra eles cometidas.

Rondon, consciente desta situação, demarcava as terras indígenas - inclusive a de São João de Jarudori - e intimava os fazendeiros para explicar os seus atos contra eles. A presença das Comissões Telegráficas no estado de Mato Grosso, entretanto, não colocou fim às violências contra os indígenas, pois os colonizadores apenas mudaram suas estratégias. Outro elemento importante a ser enfocado é o fato de que a orientação protetora de Rondon não era harmônica com as ações do Estado de Mato Grosso, que criara uma legislação estadual de colonização que deixava as terras indígenas à mercê de especuladores ${ }^{6}$.

Inseridas na categoria de "devolutas", as terras indígenas não receberam nenhum tratamento específico, "ficando apenas determinado que o governo do Estado deveria reservar terras públicas para o aldeamento dos índios mansos" (Alves de Vasconcelos, 1999, p.122), caso que excluía os Bororo Orientais, incluindo os "flutuantes".

Nesse período, o governo de Mato Grosso ofertava, via leis e decretos, incentivos oficiais para a ocupação de terras indígenas, resultando em embates sangrentos entre colonos e populações indígenas. Os novos "bandeirantes" do século XX também dispunham de um aparato legal para as suas investidas.

Rondon, por outro lado, consolidou os métodos persuasivos de "pacificação" aplicados pelo SPI (depois FUNAI), que se complementavam com o trabalho de missionários religiosos. Não há nisso incoerências ou contradições, conforme Alves de Vasconcelos (1999, p.123) “...pois, para o Estado, tanto a orientação leiga quanto a religiosa faziam parte de um mesmo processo: o processo civilizatório".

Nesse contexto, os grupos Bororo que habitavam as regiões do rio das Mortes, rio Garças, na margem direita e esquerda do rio Araguaia e o rio Vermelho, a partir do final do século XIX e início do século XX, têm suas vidas afetadas pela invasão de fazendeiros goianos e garimpeiros, resultando em intensos conflitos ${ }^{7}$. Como registrou Duroure (1977, p.199) e Corazza (1995, p.63-64): 
A situação na zona do Araguaia, no fim do século XIX e começo do XX, é esta: o bororo, dono legítimo das terras, necessita delas para a sua vida nômada: caça, pesca, colheita; o civilizado, criador de gado bovino, invade o terreno; o índio espanta o gado, mata e come rezes; o civilizado reage, mata o índio a bala e veneno; por sua vez, o índio reage e mata o invasor (guerrilhas).

Após uma primeira tentativa frustrada na Colônia Tereza Cristina, os Salesianos e Salesianas, em 1902, estabelecem-se definitivamente próximos ao rio Garças, construindo uma missão duradoura entre os Bororo, a Colônia dos Tachos, ou Sagrado Coração de Jesus, mais conhecida, na atualidade como Meruri (ver mapa 2).

Cândido Mariano da Silva Rondon, enviou ao padre Malan (superior dos salesianos), por meio de um telegrama, a seguinte mensagem de encorajamento:

... faço votos para que o vosso louvável esforço seja coroado do mais feliz êxito a bem da civilização pt. Que a posteridade agradecida vos cubra com suas benções pelos serviços prestados à família vg à Pátria vg à humanidade em desempenho da Missão a que dedicais a vida (Duroure, 1977, p.199).

Texto como este de Rondon e de outros salesianos ${ }^{8}$ evidencia como, neste período, a ideologia vigente que perpassava todas as relações com os povos indígenas, é muito semelhante. Não havia substanciais diferenças entre a catequese religiosa e aquela proposta pelo governo: ambas orientadas por princípios positivistas, com ênfase no aspecto da civilização do selvagem, ou seja, uma ação civilizatória com o objetivo de retirá-lo do estado de natureza e oferecer-lhe o modelo de cultura de uma sociedade civilizada: escrita, roupas, língua, produção e participação no mercado regional como mão de obra, entre outros.

Subordinados a uma nova ordem, os Bororo deixaram de fazer guerra, seja aos colonizadores ou outros indígenas, como os Kayapó na região do Piquiri e os Xavante, que invadiram a região do rio das Mortes, investindo contra eles no Tachos, em 1907, investidas estas que perduraram até 1935, com mortes (Albisetti; Venturelli, 1962, p.702; ver também Viertler, 1990, p.71-74).

\section{Esbulho - a expropriação forçada do território Bororo}

Através de documentos da época e, sobretudo, depoimentos dos próprios indígenas, é possível traçar rapidamente este violento processo de expropriação forçada e conseqüente diáspora ${ }^{9}$ e perda do território bororo de Jarudori, no período que vai até a década de 1980. 
O velho Coqueiro, que em suas memórias, narra suas viagens à Jarudóri e Poxoréo, afirmou: “Tinha muitos Bororo em Jarudóri. Era muitíssimo Bororo". Em Poxoréo, onde também "tinha muitos Bororo" trocavam peixes por bens que não produziam (Camargo, 2001, p.321-322). O Bororo Antonio Korobaquino, em entrevista concedida a Gilberto Kia, igualmente desse povo, lembrou-se que “...a aldeia Pocereu, hoje é a cidade de Poxoréo/MT lá moravam muitos índios bororos. [....] não demorou muito os homens brancos passaram a morar dentro das aldeias dos Boe e com isto o povo bororo foram se afastando para Jarudóri porque naquele local tornavam-se difícil a prática do funeral" (Barros; Bordignon, 2003).

Em outro depoimento o Bororo João Kaio informou que:

Com passando tempo ele relata que as doenças transmitidas pelo homem branco foram matando os bororos, a ponto que eles pediram ajuda aos índios que moravam em Jarudóri, eles vieram e levaram para lá os poucos indígenas que resistiram as epidemias (Barros; Bordignon, 2003).

Estes e outros depoimentos demonstram o quanto foi violento este processo de perda compulsória da terra, pela invasão pura e simples, com os não-índios entrando no território Bororo, trazendo como conseqüência as doenças, bebidas, destruição da natureza (fonte natural de alimentação dos Bororo), trabalhos forçados, discriminação, violência física e simbólica, entre outros.

A preocupação oficial com o leste de Mato Grosso aumentou, assim que se tornou aparente a importância estratégica e econômica da região. Em 1920, a primeira subdivisão administrativa da área de Poxoréo teve lugar, quando foram criados os Distritos de Paz de Rio Vermelho (Rondonópolis atual) e Capim Branco (Coronel Ponce). Poxoréo foi elevado a Distrito de Paz dentro do município de Cuiabá em 1932. A preocupação de integrar política e economicamente os campos de diamantes levou ao empreendimento de esforços no sentido de melhorar o sistema rodoviário (Baxter, 1988, p.83, apud Barros; Bordignon, 2003).

No contato com a frente de expansão, mas particularmente com os garimpeiros, a técnica empregada era a troca de presentes. De todos os agrados recebidos pelos índios, o que eles mais gostavam era da cachaça, que passaram a chamar de 'kudu a pemegare' que quer dizer bebida muito agradável ou boa, minha ou para mim.

Superando a eficiência dos demais pacificadores o álcool foi quem conseguiu maior e mais rápido êxito na pacificação dos Bororo. Os ferozes Coroados que, ao chegarem ao povoado garimpeiro, mostravam-se 
cismados e cautelosos, na certa lembrando-se ainda dos massacres de outrora, recebidos e revidados aos civilizados, daí a pouco, já inebriados pelos vapores do 'kudu a pemegare', misturavam-se tranqüilamente com os garimpeiros que acercavam-se deles para vê-los falar estranhamente. Em poucos dias, Bororo e garimpeiros se visitavam mutuamente, sem qualquer cerimônia ou constrangimentos. Nas noites de luar tornou-se costume os garimpeiros irem para a aldeia assistir as cerimônias dos Bororo, muito ricas em cantos e rituais (Ribeiro, 1959 apud Barros; Bordignon, 2003).

As mulheres Bororo passaram a trabalhar nas casas dos garimpeiros, revelando-se, depois de um pequeno aprendizado, excelentes domésticas. Os homens Bororo jamais quiseram trabalhar nos garimpos, mas aprenderam as lidas das roças e das fazendas, prestando serviços neste setor tão carente de mão-de-obra. O cacique era o empresário da tribo, quem ajustava o preço dos trabalhos a serem feitos por homens e mulheres Bororo e também quem, no prazo certo, ia receber o pagamento (Xavier, 1999, p.27-28).

A natureza etnocêntrica dessas relações fica bem expressa em uma passagem de Luis Sabóia Ribeiro (1959, p.234, apud Barros; Bordignon, 2003)

O trabalho para o indolente borôro é uma obrigação levada muito pouco a sério e ocupa-lhes reduzidas e espaçadas horas. Dentro das povoações ou fazendas realiza em grupo serviços mais grosseiros e, na escassez de braços, é o jornaleiro disponível eventualmente aproveitado. O que ganha, mal dá para a pinga civilizada com que a convivência o viciou, sendo ela a praga-iman que os atrai das aldeias afastadas.

Sylvia Caiuby Novaes, antropóloga e especialista em Bororo, ao escrever sobre a Missão Salesiana e a tentativa de reunir os Bororo na missão religiosa, comenta que as "dificuldades que os padres encontravam para o estabelecimento das missões não eram poucas. Acostumados a caçar e a pescar, os índios estavam habituados a percorrer seu território tradicional, nunca se estabelecendo definitivamente em um único local". Acrescenta em outro momento que "Os bororos permaneciam algum tempo na missão e logo saíam para a mata, para viverem a sua vida de sempre. Para os padres um dos maiores trabalhos era, literalmente, reunir o seu rebanho" (Novaes, 1993, p.146). Longe de imaginar uma submissão voluntária dos Bororo ao novo estilo de vida sedentária, estes comentários demonstram claramente a altivez e a persistência deste povo em manter seus costumes e práticas tradicionais de deslocamento sazonal (ver Serpa, 1988). 
Entre 1880 e 1930 as bandeiras militares foram as grandes responsáveis pelo avanço na direção oeste do país e tinham por objetivo integrar o Oeste, Nordeste e Norte sobre as quais se exercia apenas um relativo controle. As linhas telegráficas permitiram o contato com o litoral. A partir de 1930, os núcleos de colonização eram criados pelo estado de Mato Grosso, mas depois

são os empresários que vão se interessar pela ocupação do oeste brasileiro. São empresas particulares que vão comprar amplas áreas e esperar sua valorização. No leste mato-grossense, o vale do São Lourenço, a região do Alto Garças e a região sul de Dourados tornaram-se os focos de especulação fundiária (Gontijo, 1988, p.37).

Nesse contexto, os Bororo cada vez mais vão perdendo seu território, vendo suas reservas reduzidas pela expansão dos latifúndios, sem que nenhuma providência em nível estadual ou em federal lhes garantisse o domínio da terra, ainda que o SPI já tivesse sido criado há duas décadas. O mesmo vai ocorrer com a FUNAI na década de 1990.

O processo de garimpagem de diamantes, iniciado em fins do século XIX, atinge o seu apogeu na década de 40, quando as principais jazidas já estavam descobertas e a densidade populacional era maior. Este aumento populacional, de certa forma, também se deu como uma resposta à política de ocupação regional, sob o slogan da "Marcha para $o$ Oeste", desenvolvida pelo governo federal (Getúlio Vargas), que propagava as vantagens "deste oeste rico em recursos naturais e territoriais a serem conquistados" ${ }^{10}$.

O Patrimônio e distrito de Jarudori foram criados, respectivamente, nos anos de 1951 e 1958, pelo governo do Estado de Mato Grosso que, em 1945 instituíra, a Reserva "para uso dos índios bororos, do Jarudori, município de Poxoréo, área de 6.000 hectares de terra"11. No quadro abaixo, as respectivas datas de criação dos distritos de Poxoréo:

Quadro 1 - Distritos de Poxoréo: data e Decreto Lei de Criação

\begin{tabular}{|l|l|l|}
\hline \multicolumn{1}{|c|}{ Distrito } & \multicolumn{1}{c|}{ Ano criação } & Decreto Lei \\
\hline Poxoréo & 5 de março de 1938 & n.139 \\
Alto Coité & 16 de novembro de 1948 & n. 185 \\
Paraíso do Leste & 11 de Dezembro de 1953 & n. 681 \\
Jarudori & 20 de dezembro de 1958 & n. 1.191 \\
\hline
\end{tabular}


Observamos que Paraíso do Leste (onde se situava a importante aldeia Bororo Pobojári) e Jarudori tornam-se sede de distritos criados na década de 50, auge da ocupação desta região. Nesse período não somente os Bororo da Área Indígena São João de Jarudori são expropriados, mas também Pobojári, dentre outras. Os jornais da época denunciam a violenta expropriação de terras indígenas em Mato Grosso ${ }^{12}$.

Dada a dinâmica da organização social Bororo, marcada por alta mobilidade espacial e obrigações cerimoniais, sobretudo as vinculadas ao funeral, voltamos a ressaltar a importância de considerar "os Bororo de Jarudori", como sendo a nação Bororo, e não apenas o grupo que lá vivia no período da expropriação. Sabemos que os Bororo, até os dias atuais, mantêm essa dinâmica de grande mobilidade espacial, sendo, portanto, poucos os que nascem, vivem e morrem em uma mesma área.

Em termos históricos e territoriais, é impossível dissociar, também, o processo de esbulho de Jarudori - os 100.000 hectares de terras demarcadas por Rondon (São João de Jarudori) nas primeiras décadas do século XX - do processo de expropriação de outros territórios Bororo, dentro os quais temos, por exemplo, a "questão" da antiga terra de Pobojári (atual distrito de Paraíso do Leste), ainda hoje não resolvida.

Luis Carlos Okoreo (2001), professor Bororo e aluno do Projeto Tucum, comenta:

Esta área recebeu o nome de São João do Jarudóri [...] Mas na década de 40 e 50 foi sendo invadida e os Bororo, com a chegada dos brancos, foram contraindo doenças e morrendo em grandes quantidades. Sofreram também a exploração de mão-de-obra e a dispersão de várias famílias.

Dentro dos limites do território original demarcado por Rondon existiram três aldeias, mais recentes: Nabureri, Pobojári (Paraíso) e Jarudori, esta de importância ímpar, por se localizar em um território não só tradicional, mas sagrado e tematizado em mitos de origem, nos quais são invocados importantes demiurgos que organizaram social e simbolicamente o mundo dos Bororo etnograficamente conhecidos.

\section{Situação atual - após a diáspora, o processo de re-territorialização}

Os Bororo diretamente referenciados à Terra Indígena Jarudóri encontram-se, na atualidade, em três situações distintas: 1) uma família jamais saiu dessa localidade; 2) muitas famílias se encontram temporariamente dispersas em outras Terras Indígenas, sobretudo Meruri, 
Sangradouro e Tadarimana, e 3) parte da família de José Luis Kiareware vive em Cuiabá. Suas expectativas, como se verá mais adiante, voltamse para a resolução do impasse socioterritorial em que se encontram. A maioria das famílias Bororo de Jarudori, ou remanescentes delas, manifestam o mesmo sentimento e repetem a mesma fala do professor Okoreo (2001): “Nós, Boe Bororo, por motivo histórico, religioso e cultural não estamos dispostos a abrir mão de nossos direitos sobre estas terras, sobre este território Boe Bororo chamado Jarudóri".

Foi com esta força e convicção, que grupos de Bororo começaram a se mobilizar e pressionar a FUNAI e o Ministério Público Federal, na tentativa de solucionar este impasse jurídico e de omissão do Estado brasileiro diante da posse legítima desta sociedade ao seu território.

Segundo informações (Barros; Bordignon, 2003, p.268), os Bororo da região de Jarudóri buscaram o órgão tutor para reclamar da invasão de suas terras ainda no tempo do Serviço de Proteção os Índios (SPI), quando nem sequer falavam a língua portuguesa. Entretanto, jamais obtiveram resposta.

Em 18 de Agosto de 1949 foi publicado o Edital de Medição da TI de Jarudori, no Diário Oficial n. 10694, de acordo com o Decreto-Lei 684 de 18 de agosto de 1945. O Memorial descritivo foi feito por Paulo C.S. Campos e no seu registro de "Benfeitorias", datado de 18 de novembro de 1949, tem-se o seguinte: "dentro da área medida possuem os índios bororos alguma benfeitoria constante de pequenas roças, além de 08 choupanas de palha que formam a aldeia. Ainda nestas terras tem a sua morada habitual, várias famílias, muitas das quais cultivam a terra e tem as suas casas junto à Estação Telegráfica, no entroncamento das linhas Rondonópolis-Guiratinga e Rondonópolis-Poxoréo" (op.cit. 268).

Ao longo deste período de intrusão e expropriação do território Bororo de Jarudori, outras ações de denúncia e reivindicações foram realizadas pelos Bororo, sobretudo nas décadas de 80 e 90, mas sem nenhum eco nos órgãos oficiais.

Diante deste histórico descaso, como nenhuma providência de fato foi tomada ao longo dos anos, os Bororo decidiram promover uma grande Assembléia, reunindo representantes de todas as Terras Indígenas, em 1983. Ela aconteceu na Terra Indígena Meruri (aldeia do Garças), contando com a participação de líderes de todas as aldeias Bororo e alguns convidados de outras etnias, além de jornalistas, representantes da Operação Anchieta, do Conselho Indigenista Missionário, da Missão Salesiana, entre outros. A coordenação da reunião foi feita pelos próprios líderes do movimento e a questão da terra foi o tema dominante no encontro ${ }^{13}$. 
Após esta ação e inúmeros outros processos e cartas às autoridades (ver Barros; Bordignon, 2003, p.268-295) levados a cabo pelos Bororo, foi constituído um GT visando a resolver a problemática que envolve a T.I. Jarudori, conforme relatado anteriormente. A este processo reivindicatório e de mobilização dos líderes Bororo de todas as aldeias para a efetiva retomada de suas terras de jarudori, chamamos de processo de reterritorialização.

Os conceitos de territorialidade e territorialização têm revelado uma eficácia especialmente relevante para a discussão destas questões. (cf. Little, 2002). No contexto histórico, terra e territorialidade se entrelaçam como espaço físico e espaço sociopolítico. No caso dos Bororo, ao mesmo tempo em que se dá a diáspora, ou seja, a expulsão de seu território e dispersão socioterritorial, a re-ocupação do espaço físico pelos indígenas caracteriza o processo inverso que chamamos re-territorialização.

Entende-se aqui a territorialidade como modo de delimitação e manifestação histórico-cultural das identidades coletivas dos sujeitos sociais indígenas, pelo qual a diversidade de seus interesses e necessidades ganha visibilidade e legitimidade. As territorialidades se definem, portanto, na luta política e na afirmação e defesa de direitos sociais. Neste sentido, a noção de território social é importante para dar visibilidade aos modos indígenas de pertencimento a um lugar, ou seja, as condições de reprodução sociocultural do modo de vida Bororo.

Como modelo abstrato, o conceito de territorialidade pode contribuir para superar as limitações do paradigma fragmentado do olhar técnico convencional, redirecionando-o para uma visão de complexidade onde espaço físico e dimensão sociocultural se articulam organicamente (cf. Little, 2002). Ou seja, no caso dos Bororo, é a possibilidade de perceber a importância de sua organização social e relações de parentesco e do esforço coletivo pelo qual se dá o controle social sobre o ambiente biofísico (território), por meio da complementaridade entre a base material e ideológica: os regimes de ocupação e uso do solo, as práticas e os conhecimentos ecológicos que informam as técnicas de produção, os saberes e representações identitárias, a memória coletiva e a autonomia cultural, entre outros.

Por desterritorialização, podemos entender os efeitos de extermínio, de expropriação, de deslocamento forçado e ruptura das relações sócio-históricas, que destroem a integridade da relação entre a base material eideológica das populações sobre as quais se aplicam. Citamos, neste caso, o processo de expropriação ocorrido com os Bororo de Jarudori, no século XX. 
Por outro lado, a re-territorialização refere-se aos processos pelos quais os Bororo engajam-se em movimentos de re-apropriação e retomada de seu território ancestral, tais como os descritos neste trabalho. Neste sentido, mesmo não tendo ainda assegurada a posse definitiva da terra com a desintrusão dos não-índios, na atualidade, vieram para Jarudori apenas cinco famílias Bororo que resolveram retornar para lutarem por suas terras, a partir de dentro ${ }^{14}$. Desde então convivem com ameaças e em situação precária.

A líder deste movimento de retorno à terra é a cacique Maria Aparecida Toro Ekureudo. Segundo matéria do Jornal Diário de Cuiabá (25/6/6), ela afirma que "Isso aqui é terra nossa. É demarcada e homologada. Já tem muitos anos que esperamos uma atitude das autoridades, sem solução. A maioria quer voltar para o Jarudori, para a aldeia velha. Viemos para mostrar que não nos esquecemos de nossa terra e para encorajar outros a fazer o mesmo e nos ajudar".

\section{Conclusão}

O povo Bororo, que se autodenomina Boe, que ocupava até fins do século XVIII grande parte do centro sul do atual estado de Mato Grosso, após mais de um século de contato intermitente com o entorno regional e com a atuação de missionários e de órgãos do Estado, na atualidade estão reduzidos a um pouco mais de mil pessoas vivendo em 6 terras indígenas, sendo uma delas, Jarudori que, apesar de demarcada e homologada, está totalmente ocupada por fazendeiros e uma pequena cidade.

Esta área dos Bororo foi demarcada pela primeira vez em 1912 por obra de Cândido Rondon, logo após a criação do SPI. São João de Jarudóri, como foi chamada, tinha como marcos referenciais alguns dos morros típicos da região de Poxoréo e somava cerca de 100 mil hectares (ver seção Iconografia, p. 149). Em 1945, um decreto estadual - n. 644/45 redefiniu os limites da área para 6 mil hectares, menos de um décimo do desenho original. Seis anos mais tarde, em 1951, um título definitivo expedido pelo governo do Estado fixou a terra indígena Bororo em 4,7 mil hectares. Como se não bastasse, essa área foi a seguir fruto de invasões e loteamentos irregulares, contando sempre com a omissão - e, muitas vezes, o incentivo - das autoridades.

Os moradores não-índios do distrito de Jarudori não negam a particularidade das terras que ocupam (sabem que são dos Bororo), mas alegam que tomaram posse de áreas abandonadas e até vendidas pelos 
índios. Como sabemos e tentamos demonstrar com este texto, o processo de expropriação foi lento, porém violento, em que tentativas explícitas de intimidação se juntavam à total falta de apoio oficial.

"O governo é o maior culpado por esta invasão. A Funai, por exemplo, cruzou os braços, enquanto o problema ia aumentando", diz a cacique Maria Aparecida. “Enquanto isso, outros ficavam por trás, dando incentivo, autorizando o pessoal a entrar. Mas a verdade é que todo mundo sabia que aquela área é indígena" (Jornal Diário de Cuiabá 25/06/06).

Para o povo Bororo, o território é base material concreta para sua sobrevivência física, política e cultural. Jarudori é, nesse sentido, um destes espaços territoriais densamente marcado por processos identitários deste povo. Sem falar da qualidade das terras e da abundância de flora e fauna, os morros de Jarudori permeiam o imaginário e a mitologia dos Bororo, assim como alguns de seus cantos e rituais. Retornar a esta terra imemorial é, antes de tudo, conforme Oliveira (1993):

A atribuição a uma sociedade de uma base territorial fixa que se constitui em um ponto-chave para a apreensão das mudanças por que ela passa, isso afetando profundamente o funcionamento das suas instituições e a significação de suas manifestações culturais.

Assim, o movimento de retorno para as terras de Jarudóri, significa a retomada de um novo processo sociocultural para estas famílias, muitas delas remanescentes dos antigos moradores originais da aldeia de Jarudóri. Para muitas dessas famílias, são mais de 50 anos fora de seu espaço territorial, vivendo em outros núcleos familiares e, até mesmo, em periferias de grandes cidades. Na tentativa de compreensão dos elementos que compõem esse fenômeno e utilizando as palavras de Oliveira (1998), tempos que

A noção de territorialização é definida como um processo de reorganização social que implica: 1) a criação de uma nova unidade sociocultural mediante o estabelecimento de uma identidade étnica diferenciadora; 2) a constituição de mecanismos políticos especializados; 3) a redefinição do controle social sobre os recursos ambientais; 4) a reelaboração da cultura e da relação com o passado.

Em outras palavras, esse grupo étnico volta a se organizar em torno da reconquista da terra, utilizando para isso, suas diferenças culturais, lançando mão da história de seus antepassados (mitologia, graus de parentesco, elementos materiais e simbólicos, língua, entre outros) e, sobretudo, da própria história de contato com os não-indígenas, que em um passado recente lhes haviam garantido este território (por exemplo, a demarcação de 100 mil ha realizada por Rondon). 
Em termos jurídicos, na atualidade, corre na justiça uma ação cível do Ministério Público Federal, contra a União e contra a FUNAI (por não tomarem nenhuma atitude em todo este período de invasão das terras indígenas), solicitando a reintegração de posse das terras de Jarudóri.

A seguir, o depoimento de Gustavo Baiporo ex-cacique de Meruri sobre a situação dos Bororo e da Terra Indígena Jarudori:

“Nós aqui, pessoas da minha época, de minha geração, nós estamos totalmente indignados, porque... Jarudóri sempre foi uma terra pra nós que, há muito tempo a gente já ouviu falar em Rondon, que tinha deixado essa herança... [...] Agora a indignação é muita pra nós, que somos jovens agora, porque nós perdemos várias partes do que nós tínhamos. E até as vezes estamos sendo massacrados até por não ter tanta importância como índio. E essa indignação deixa a gente muito assim abaixo, sempre de favores, como se a gente fosse pedir favores pra alguém, como se fosse pedir socorro pra alguém.. [....] acredito que nós perdemos a maior parte de nosso direito até porque tem várias cidades aqui em Mato Grosso, a própria Cuiabá, que é a capital daqui, tem Corumbá, tem Batovi, tem Torixoréu, a própria Poxoréo, que é perto dali... tem várias praças originais... que nasceram com a gente ali, nossa tradição, deixamos traços nas pedras, nos rios, nos lagos, onde Bororo sempre deixa uma coisa da nossa cultura, restos mortais... Com Jarudóri não é diferente. Em Jarudóri nós perdemos uma maior parte da terra, nós sabemos que tinha muita terra... [...] Eu queria falar apenas da indignação, que nós temos a área lá, a nossa herança... que todo mundo pode passar ali por Jarudóri que tem o nome do local ali [...] em todo o Mato Grosso, entrando por Goiás adentro tem vários nomes, tem vários traços, tem muita coisa, deixamos abandonadas várias aldeias, deixamos tudo para vivermos aqui, pra viver fechados num canto, sendo espremidos num canto. Nós não podemos pensar nisso. Hoje a juventude está pensando em outra vez resgatar tudo aquilo que não acabou, mas apenas foi modificado. Nós temos uma história muito longa. É um povo muito aguerrido, altivo, nós não podemos deixar isso acabar assim" (cf. Barros; Bordignon, 2003).

\section{Notas}

${ }^{1} \mathrm{O}$ presente artigo está todo fundamentado no trabalho realizado pela profa. Dra. Edir Pina de Barros (Antropóloga) e o Historiador Mário Bordignon, a pedido da FUNAI e do Ministério Público Federal, em 2003. Ver bibliografia: Barros; Bordignon, 2003.

${ }^{2}$ Todas as referências bibliográficas sobre os Bororo, em perspectiva histórica, registram a demarcação dessas terras por Rondon, embora não se tenha conseguido, ainda, localizar os documentos relativos a ela. Esse fato teria ocorrido - de acordo com um documento oficial do SPILTN, de 1915. 
${ }^{3}$ A grafia Poxoréo é utilizada como transcrição da oralidade indígena. O município foi registrado como Poxoréo.

${ }^{4}$ Grupo técnico: Antropóloga Edir Pina de Barros (coordenadora), Mário Bordignon (historiador e profundo conhecedor do povo e da cultura Bororo), Antônio Domingos de Andrade, funcionário da FUNAI, lotado na AER/Cuiabá (motorista).

${ }^{5}$ Os salesianos atuaram junto aos militares, em 1895, na Colônia Teresa Cristina, no rio São Lourenço. A partir de 1902 fundaram suas próprias colônias, com fins religiosos e educacionais, tendo por paradigma seus projetos próprios, que se adequavam a uma política indigenista nacional, de cunho integracionista.

${ }^{6}$ Em 1892 criou a Diretoria de Obras Públicas, Terras, Minas e Colonização, encarregada de elaborar projetos, leis, regulamentos, para esse fim: "Além da venda de terras por um preço irrisório a imigrantes nacionais e estrangeiros, todas as terras consideradas devolutas, àquelas que não aplicadas a algum uso público federal, estadual ou municipal; e as que se acham no domínio particular por título legítimo ' (.....), ficaram sujeitas à apropriação por particulares"' (Alves de Vasconcelos, 1999, p.121).

${ }^{7}$ As relações entre os Bororo e os fazendeiros em Goiás e na área do Garças “...nem sempre se deram de forma pacífica e o refluxo dos Bororo de Goiás, o qual envolvia muita gente, parece ter-se dado junto com a expansão agro-pastoril na virada deste século [XX]. Fato que explica a extrema belicosidade e que é claramente expressa na afirmação do Bororo Casimiro, cuja mãe nasceu em Goiás, de que 'os Bororo de Goiás realmente eram bravos' e ao atravessar o rio Araguaia fundaram uma grande aldeia chamada Koitoguru" (Wust, 1990, p.99) na barra do rio Areia com o rio Vermelho.

8 "Oh! Que campo immenso para o valor e abnegação dos valentes soldados da cruz e do progresso! [...] É sabido por todos que aquelles infelizes andam completamente nús, e os missionários logo ao chegarem deverão tratar antes de tudo de cobri-los, e dar-lhes pouco a pouco aspecto de gente, pois que no estado em que presentemente se acham não diferem muito das féras do matto". Carta de Dom Lasagna, escrita em São Paulo, dia $1^{\circ}$ de Janeiro de 1895, antes mesmo de iniciarem os trabalhos em Mato Grosso, distribuída por todo país pedindo auxílio para as missões. Reproduzida em Castilho, 2000, p.36-42.

${ }^{9}$ Este conceito passou a ter um lugar central nas ciências sociais e, particularmente, nos chamados Cultural Studies. Entendemos diáspora aqui, como sendo um conceito que vem desde os antigos gregos, para os quais "diáspora" (dispersão, ou semear) estava associado a idéias de migração e colonização na Ásia Menor e no Mediterrâneo na Antiguidade. Na era moderna, o termo tem sido usado como auto-descritivo pelas comunidades fora de seu território original e em situação de opressão e de vitimização, em que o eu é confinado dentro do território do outro. Comunidades em diáspora, como é o caso dos Bororo de Jarudori, são aquelas que compartilham a existência de uma história comum, de expulsão violenta de uma terra-mãe, uma projeção histórica de pureza e de intemporalidade sobre a terra-mãe, sonhos de reatar com a terra-mãe e de lá regressar, um esforço coletivo de assimilação no seio de culturas hostis, e marginalização, muitas vezes prolongando-se por gerações, com base em alegadas diferenças étnicas, religiosas ou raciais na nova pátria.

${ }^{10}$ Getúlio Vargas, discurso pela passagem do ano de 1937, no Palácio das Laranjeiras. 
Apud Gontijo, 1988, p.6, nota de pé de página n. 2.

${ }^{11}$ Rosa de Amorim (2001, p.105) apud. Barros \& Bordignon, 2003.

${ }^{12}$ Acervo do Museu do Índio da FUNAI, no Rio de Janeiro: documento, datado de 9 de novembro de 1954, encaminhado pelo chefe da $6^{\text {a }}$ Inspetoria Regional, Beinjamin Duarte Monteiro, ao Diretor do Serviço de Proteção aos Índios no Rio de Janeiro (DF): “O vibrante editorial 'Mato Grosso à venda', do Correio da Manhã de 30 de outubro último devia ser conhecido de todos os Chefes e Auxiliares das Inspetorias do nosso Serviço afim de que os mesmos se manifestassem a respeito, dando a sua solidariedade a essa meretória campanha ora iniciada pelo conceituado matutino carioca em defesa das terras dos índios". Sugere a sua distribuição "aos chefes de todas as Inspetorias \{.... Para o dossier da Diretoria, mando incluso dois números, de 7 do corrente, do 'Estado de Mato Grosso', jornal independente que se edita nesta Capital e que, gentilmente, transcreveu do 'Correio da Manhã' o artigo de Otto Prazeres sobre a inconstitucionalidade das concessões de terras que o Governo de Mato Grosso vem fazendo, alguma dos quais em prejuízo do patrimônio indígena" (Monteiro, 1954, F. 380 e F. 1689; apud. Barros; Bordignon, 2003).

${ }^{13}$ A repercussão dessa Assembléia foi grande, sendo bastante divulgada na mídia. A título de ilustração citamos as seguintes reportagens (cf. Barros, 1983):

1) Isto É, 24/8/83, n. 348, ano 7 e pg. 33 "Rompimento de Relações";

2) Revista Contato, ano V, n.43, agosto/setembro de 1983 - "Pacto de União" Reunião dos Borôro é marco de luta por direitos;

3) Isto É, 28/9/93 - "Os Bororo brandem a borduna";

4) Jornal Tribuna Cuiabana, Cuiabá, 25/9/83 - "Borôros poderão se revoltar contra o descaso da FUNAI";

5) Díario de Cuiabá, 23 de setembro de 1983 - "Índios podem entrar em guerra: as acusações da FUNAI à cacique podem levar os Borôros a uma reação";

6) Porantim, ano VI, n. 56, outubro de 1983 - "I Encontro dos Líderes Borôro: União e fim do Silêncio".

${ }^{14}$ O Jornal Diário de Cuiabá (25/06/06) fala que "um grupo de famílias da etnia Bororo decidiu iniciar por conta própria a retomada dos 4,7 mil hectares da Terra Indígena Jarudori, demarcada e homologada para a etnia há mais de 50 anos, mas que foi invadida e hoje abriga o distrito de Jarudori, no município de Poxoréo (259 quilômetros de Cuiabá). Na próxima semana, o Ministério Público Federal ingressará com uma ação de reintegração de posse em favor dos índios. Dizendo-se cansados de esperar pela justiça, eles escolheram a área de uma antiga fazenda de gado, atualmente desativada, para iniciar a construção da 'Aldeia Nova', a menos de 5 quilômetros da área urbana do distrito”. No Jornal Diário de Cuiabá (Edição n. 11759 08/03/2007) trata do Relatório do Departamento de Estado Norte Americano, em que sita entre outras situações contrárias aos direitos humanos em Mato Grosso, a questão "da área indígena Jarudori (em Poxoréo), cuja propriedade é de um grupo de bororos, que voltam a ocupar a terra disputando o espaço também com posseiros". 


\section{Referências}

ALBISETTI, Cesar. E.; VENTURELLI, Ângelo. J. Enciclopédia Bororo I, Campo Grande, 1962.

ALVES DE VASCONCELOS, Cláudio. A questão indígena na Província de Mato Grosso: Conflito, trama e continuidade. Campo Grande: Editora da Universidade Federal de Mato Grosso do Sul, 1999.

BARROS, Edir Pina de; BORDIGNON, Mário. Jarudori - Estudos e Levantamentos Prévios Histórico-Antropológicos. Relatório relativo ao Termo de Referência DAF/ DEID n. 53/2002, do Departamento de Identificação e Delimitação da Diretoria de Assuntos Fundiários/FUNAI - Brasília, 2003.

BARROS, Edir Pina de. Movimentos Indígenas em Mato Grosso. In: $7^{\circ}$ Encontro Anual da Associação Nacional de Pós-Graduação e Pesquisa em Ciências Sociais. Águas de São Pedro , 26 a 28 de outubro de 1983.

. Os filhos do sol. São Paulo: EDUSP, 2003.

. Laudo Histórico-Antropológico: Ação de Desapropriação Indireta (Processo 17.624/86). In: MALDI, Denise (Org.). Direitos indígenas e Antropologia: laudos periciais em Mato Grosso. Cuiabá: Editora da UFMT, p.96-174, 1994.

BORDIGNON, Mario. Róia e Baile. Mudança Cultural Bororo. Campo Grande: Editora UCDB, 2001.

CAMARGO, Pe. Gonçalo Ochoa (Org.). Meruri na visão de um ancião Bororo: Memórias de Frederico Coqueiro. Campo Grande: Editora da UCDB, 2001.

CASTILHO, Maria Augusta de. Os indios Bororo e os salesianos na Missão dos Tachos. Campo Grande: Editora UCDB, 2000.

COLBACCHINI, Antonio; ALBISETTI, César. Os Bororos orientais. Cia. Ed. Nacional, Série Brasiliana, Grande Formato, 1942 (I Bororos Orientali Orarimugudoge del Matto Grosso, Brasile, Itália, 1925).

CORAZZA, Pe. José. Esboço histórico da Missão Salesiana em Mato Grosso. Campo Grande: Missões Salesianas de Mato Grosso, 1995.

DAL POZ, João. Laudo antropológico: A ocupação indígena no Parque Nacional do Xingu e adjacências. $2^{\mathrm{a}}$ Vara da Justiça Federal, Seção Judiciária do Estado de Mato Grosso, Processo n. 1997.36.00.005648-9. Classe 06300, Carta de Ordem. Autor: Estado de Mato Grosso. Réu: União Federal, 2001.

DUROURE, Pe. João Batista. Dom Bosco em Mato Grosso. I Volume: 1894-1904. Campo Grande: Missões Salesianas de Mato Grosso, 1977.

GONTIJO, Nicozina Maria Campos. O brilho e a miséria: A exploração de diamantes em Poxoréo-MT (1930-40). Dissertação (Mestrado em História) - UnB, Brasília, 1988.

LITTLE, Paul. Territórios Sociais e Povos Tradicionais no Brasil: por uma Antropologia da territorialidade. Serie Antropologia. Brasília: UnB, 2002.

MACIEL, Laura Antunes. A Nação por um fio: Caminhos, práticas e imagens da "Comissão Rondon". São Paulo: Editora da PUC/SP- FAPESP, 1998.

NOVAES, Sylvia Caiuby. Jogo de espelhos. Imagens de representação de si através dos 
outros. São Paulo: Editora da Universidade de São Paulo, 1993.

OKOREO, Luiz Carlos. Terra de Jarudori Trabalho final do Projeto Tucum, Pólo IIIBoe Bororo. Rondonópolis, Secretaria de Educação do Estado de Mato Grosso/ Município de Rondonópolis, fevereiro de 2001.

OLIVEIRA, João Pacheco de. As Sociedades indígenas e seus Processos de Territorialização. In: $3^{a}$ Reunião de Antropólogos do Norte e Nordeste. ABA/UFPA. Belém: 1993.

Uma etnologia dos "índios misturados"? Situação colonial, territorialização e fluxos culturais. Mana, Rio de Janeiro, n.4, v.1, p.47-77, 1998.

. A viagem da volta: etnicidade política e reelaboração cultural do nordeste indígena. Rio de Janeiro: Contra Capa Livraria, 1999.

SERPA, Paulo Marcos Noronha. Bóe Épa. O Cultivo de Roça entre os Bororo do Mato Grosso. Dissertação (Mestrado em Antropologia Social) - FFLCH/USP, São Paulo, 1988.

SOUZA LIMA, Antônio Carlos de. O Governo dos índios sob a gestão do SPI. In: CARNEIRO DA CUNHA, Manuela (Org.). História dos índios no Brasil. São Paulo: Companhia das Letras/Secretaria Municipal de Cultura/FAPESP, 1992.

VANGELISTA, Chiara. Missões Católicas e políticas tribais na frente de expansão: os Bororo entre o século XIX e o século XX. Revista de Antropologia, São Paulo, v.39, n. 2, p. 165-197, 1996.

VIERTLER, Renate B. As duras penas: Um histórico das relações entre os índios Bororo e "civilizados" no Mato Grosso. São Paulo, FFLCH/ USP, 1990.

WÜST, Irmhild. Continuidade e Mudança - Para uma interpretação dos grupos ceramistas pré-coloniais da Bacia do Rio Vermelho, Mato Grosso (Volumes I e II). Tese ( Doutorado em Antropologia Social) - FFLCH/USP, São Paulo, 1990.

XAVIER, Jurandir da Cruz. Poxoréo e Garças. A Saga dos Garimpeiros. Cuiabá: Edições Calendário do Sol, 1999.

Recebido em 02 de janeiro de 2007.

Aprovado para publicação em 05 de fevereiro de 2007. 
